\title{
Cyclic fatigue resistance of novel Genius and Edgefile nickel-titanium reciprocating instruments
}

Carlos Roberto Emerenciano BUENO(a) Marina Tolomei Sandoval CURY(a) (i) Ana Maria Veiga VASQUES(a) Gustavo SIVIERI-ARAÚJO(a) Rogério Castilho JACINTO(a) João Eduardo GOMES-FILHO(a) Luciano Tavares Angelo CINTRA(a) Eloi DEZAN-JÚNIOR ${ }^{(a)}$

(a) Universidade Estadual Paulista- UNESP, Araçatuba School of Dentistry, Department of Endodontics, Araçatuba, SP, Brazil.
Declaration of Interests: The authors certify that they have no commercial or associative interest that represents a conflict of interest in connection with the manuscript.

Corresponding Author: Eloi Dezan-Junior

E-mail: dezan@foa.unesp.br

hitps://doi.org/10.1590/1807-3107bor-2019.vol33.0028

Submitted: August 30, 2018

Accepted for publication: January 14, 2019

Last revision: March 08, 2019
Abstract: This study aimed to assess the cyclic fatigue resistance of Genius and EdgeFile X1 reciprocating instruments compared with WaveOne Gold Primary. Twenty Genius (Ultradent) 25.04, 20 Genius 30.04, 20 EdgeFile X1 (EdgeEndo) and 20 WaveOne Gold Primary (Dentsply Maillefer) instruments were included in this study and tested in a static cyclic fatigue testing device, which has an artificial stainless steel canal with a $60^{\circ}$ angle of curvature and a 5-mm radius of curvature. All instruments were operated in reciprocation mode until fracture occurred. The number of cycles to failure (NCF) was calculated and time to fracture (TF) was recorded in seconds using a digital chronometer. The mean and standard deviations of NCF and TF were calculated for each reciprocating system and the data were subjected to Kruskal-Wallis one-way analysis of variance and to Dunn's test $(p<.05)$ using SigmaPlot software (Systat software, CA, USA). The fractured surfaces of five instruments from each brand were randomly examined and microphotographed by a low-vacuum environmental scanning electron microscopy - SEM (Tabletop Microscope TM3030, Hitachi, Japan) to confirm the cyclic fatigue fracture. EdgeFile exhibited the highest cyclic fatigue resistance, followed by both Genius files $(p<.05)$. Within the limitations of this in vitro study, EdgeFile X1 instruments had significantly higher cyclic fatigue resistance than did Genius and WaveOne Gold Primary instruments. The cyclic fatigue resistance of both Genius files was higher than that of WaveOne Gold Primary.

Keywords: Dental Instruments; Endodontics; Root Canal Preparation.

\section{Introduction}

Endodontic instruments manufactured with nickel-titanium (NiTi) were introduced by Walia et al. ${ }^{1}$ to improve the instrumentation of curved canals, once NiTi instruments are more flexible and have superior resistance to torsional fracture compared with the rigidity of stainless steel instruments, reducing canal transportation. ${ }^{2,3}$ In addition, operator fatigue, procedural errors, and length of root canal treatment ${ }^{4}$ are reduced, improving the quality of endodontic therapy for both the professional and the patient.

Despite the advantages of NiTi, fracture incidence is the most common failure that occurs during its use $\mathrm{e}^{5}$ as a result of flexural or torsional strength, 
or even a combination of both, ${ }^{6}$ without any visible indication of plastic deformation. ${ }^{7}$ Therefore, the manufacturers recommend limited or even single-time use of NiTi instruments, especially in curved canals.

The metal fatigue caused by repetitive stressing cycling is an important failure mechanism. ${ }^{8}$ In this fracture type, also known as cyclic fatigue, $\mathrm{NiTi}$ instruments undergo tension and compression forces in the area of maximum canal curvature, until fracture. 9 Several studies have shown that reciprocating motion enhances cyclic fatigue resistance compared to rotation motion, ${ }^{10,11,12}$ making reciprocating instruments safer than rotary ones for root canal shaping.

WaveOne Gold (Dentsply Maillefer, USA) is available in the market as a single-file technique, with Small (20.07), Primary (25.07), Medium (35.06), and Large (45.05) instruments as recent versions of WaveOne (Dentsply Maillefer). It is manufactured with a gold heat treatment procedure, which is performed by heating the file and then cooling it slowly, in contrast to the pre-manufacturing heat treatment of M-Wire technology. The reciprocating motion of WaveOne was maintained, with a cutting action at $150^{\circ} \mathrm{CCW}$ and disengagement at $30^{\circ}$ in the $\mathrm{CW}$ direction, but the file dimensions and geometry differ from the original WaveOne, featuring an offcenter design with cutting edges and alternate 1-point contact in a parallelogram design. Also, Wave One Gold instruments have a different taper in the same instrument, as WOG Primary starts with a 25.07 tip, decreasing to .06 after $4 \mathrm{~mm}$ and to .03 after another $4 \mathrm{~mm} \cdot{ }^{13,14}$

The Genius system (Ultradent, South Jordan, UT) has been recently developed to associate rotary and reciprocating techniques, with thermally treated NiTi alloy and a .04 taper, improving resistance and flexibility, as announced by the manufacturer. Rotary motion is indicated to enlarge the cervical third, and two reciprocating files are used to prepare the root canal, with $90^{\circ}$ of cutting action $(\mathrm{CW})$ and $30^{\circ}$ of release (CCW). The instrumentation finishes with a $360^{\circ}$ rotation, removing the debris from the canal. The files have an S-shaped cross-section design with double right positive cutting action and, according to the manufacturer, the progressive pitch of the file during instrumentation prevents the "screw-in" effect. ${ }^{15}$
The EdgeEndo company (Albuquerque, USA) has launched several automated instruments such as reciprocating $(\mathrm{X} 1)$, rotary $(\mathrm{X} 3, \mathrm{X} 5$ and $\mathrm{X} 7)$, or retreatment (XR) endodontic files. EdgeFile X1 (EdgeEndo) features a constant .06 tapered reciprocating instrument with a triangular cross-section and annealed heat-treated nickel-titanium alloy (Fire-Wire ${ }^{\mathrm{TM}}$ ), which according to manufacturer, increases flexural strength, enhancing durability and flexibility. The files must be used in the WaveOne ${ }^{\circledR}$ motor setting, therefore with the same motion of $150^{\circ}(\mathrm{CCW})$ cutting action and $30^{\circ}(\mathrm{CW})$ release, as recommended by the manufacturer. ${ }^{16}$

To date, there have been no studies on the cyclic fatigue resistance of reciprocating Genius and EdgeFile systems in curved canals. Therefore, the present study aimed to compare the cyclic fatigue resistance of Genius and EdgeFile reciprocating files with WaveOne Gold Primary instruments. The null hypothesis was that there would be no significant difference in the cyclic fatigue resistance of the instruments.

\section{Methodology}

In this study, 80 files were selected $(n=20)$, as previously used for cyclic fatigue tests, ${ }^{17,18,19,20}$ as follows: 20 Genius (25.04), 20 Genius (30.04), 20 WaveOne Gold Primary (25.07), and 20 EdgeFile X1 (20.06) files. To measure the cyclic fatigue resistance of the files, an artificial canal, made of stainless steel with an inner diameter of $1.5 \mathrm{~mm}$, a $60^{\circ}$ angle of curvature, and a curvature radius of $5 \mathrm{~mm}$, was used. The curvature of the artificial canal was located at the 5-mm coronal end of the canal. ${ }^{21,22}$ To reduce the friction of the files as they contacted the artificial walls of the canal, a synthetic oil (WD-40 Company, Milton Keynes, UK) was used for lubrication. ${ }^{22}$ All cyclic tests were performed at room temperature $\left(20^{\circ} \pm 1^{\circ} \mathrm{C}\right)$.

The files were divided into four experimental groups ( $n=20)$ and underwent the following procedures:

a. Group 1: Genius 25.04: The files were used with the Genius reciprocating \& rotary motor (Ultradent Products, Inc, South Jordan, USA) connected to a cyclic fatigue testing instrument and operated at $350 \mathrm{rpm}$, set to the genius files in reciprocation mode, with $90^{\circ}$ of cutting action (CW) and $30^{\circ}$ of release $(\mathrm{CCW})$, until they fractured. 
b. Group 2: Genius 30.04: The files were used with the Genius reciprocating \& rotary motor (Ultradent Produtcs, Inc, South Jordan, USA) connected to a cyclic fatigue testing instrument and operated at $350 \mathrm{rpm}$, set to the genius files in reciprocation mode, with $90^{\circ}$ of cutting action (CW) and $30^{\circ}$ of release $(\mathrm{CCW})$, until they fractured.

c. Group 3: WaveOne Gold Primary: The files were used with the E3 Torque Control Motor (Dentsply Tulsa Dental Specialties, USA) connected to the cyclic fatigue testing instrument and operated at $350 \mathrm{rpm}$ with the "WaveOne ALL" program until they fractured.

d. Group 4: EdgeFile X1: The files were used with the E3 Torque Control Motor (Dentsply Tulsa Dental Specialties, USA) connected to the cyclic fatigue testing instrument and operated at $350 \mathrm{rpm}$ with the "WaveOne ALL" program, as recommended by the manufacturer, until they fractured.
All the instruments were reciprocating and time from motor activation was recorded and stopped as soon as a fracture was detected visually and/or audibly on a digital chronometer. The number of cycles to failure (NCF) of each file was then calculated using the following formula: $\mathrm{NCF}=$ revolution per minute (rpm) X time (seconds)/60. The lengths of the fractured segments were measured by a digital caliper (Mitutoyo, Absolute Digimatic, Japan).

The fractured surfaces of five instruments from each brand, randomly selected after the cyclic fatigue test, were examined by a low-vacuum environmental scanning electron microscopy - SEM (Tabletop Microscope TM3030, Hitachi, Japan), in order to confirm that the files fractured because of the cyclic fatigue, ${ }^{17,21}$ and photomicrographs of the fractured surfaces were taken, as shown in Figure 1. Before SEM evaluation, the instruments were ultrasonically cleaned to remove any debris. ${ }^{22}$

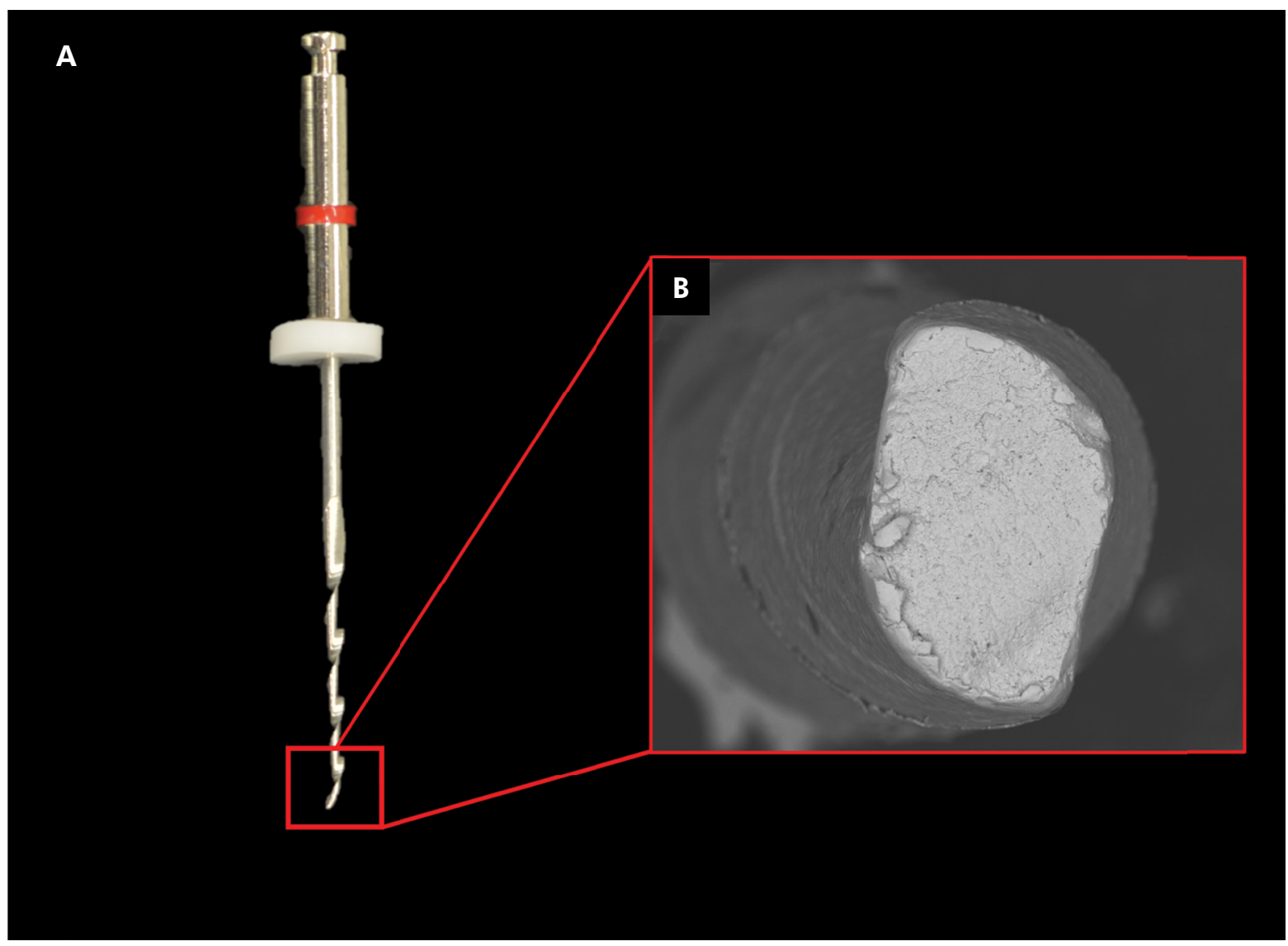

Figure 1. Illustrative example of a Genius 25.04 broken file after reciprocation inside the simulated canal, evidencing the area of analysis (A) and a SEM image (B), showing the analyzed inspection area of a cyclic fatigue ductile fracture. 


\section{Statistical analyses}

The data were first analyzed using theShapiro-Wilk test to verify the assumption of normality. The Kruskal-Wallis and Dunn's tests were performed using SigmaPlot software (Systat Software, San Jose, USA) to statistically analyze the data. The statistical significance level was set at $p<.05$.

\section{Results}

The means and standard deviations of the NCF, time to fracture, and the lengths of fractured segments are shown in Table. EdgeFile X1 had the highest fatigue resistance (NCF: $6175.74 \pm 1608.99$; TF: $1058.7 \pm 275.82$ ) while Wave One Gold Primary had the lowest fatigue resistance (NCF: $881.7 \pm$ 108.04; TF: $151.15 \pm 18.52$ ) with a statistical difference $(\mathrm{p}<.05)$. The fatigue resistance of both Genius 25.04 (NCF: $1217.12 \pm 230.36$; TF: $208.65 \pm 39.49$ ) and 30.04 (NCF: $1365.58 \pm 224.81$; TF: $234.10 \pm 38.56)$ was statistically higher than that of Wave One Gold Primary $(881.7 \pm 108.04)(p<0.05)$, but presented no significant difference between the Genius instruments $(\mathrm{p}>0.05)$.

The mean lengths of fractured segments were recorded in order to evaluate the correct positioning of the tested files inside the canal curvature, since each group maintained the approximate segment length. There was a statistically significant difference $(p<.05)$ in the mean length of the fractured fragments among all instruments, except for Genius 25.04 and EdgeFile X1 (Table).

\section{SEM evaluation}

Scanning electron microscopy images of the fractured surface showed typical features of cyclic fatigue failure for all instruments. All the instruments presented fractured surfaces with microvoids, a mechanical characteristic of ductile fracture (Figure 2).

\section{Discussion}

Since the introduction of NiTi instruments in endodontics by Walia et al. ${ }^{1}$ in the 1980s, manufacturers have been improving the manufacturing process, aiming to enhance the mechanical properties of the alloy and decreasing the failures (broken files) observed during the endodontic treatment. ${ }^{23}$ Nowadays, NiTi endodontic files are classified into instruments containing mainly the austenite phase, such as conventional NiTi, M-Wire, or R-Phase, and those containing mainly the martensite phase, such as CM Wire, Gold, and Blue (thermally treated). The instruments in the austenite phase show superelastic properties and high torque values, indicated for shaping straight or slightly curved canals or even as pathfinding instruments because of the smaller diameter. Martensitic instruments are more flexible, used in root canals with severe or double curvature, in addition to being prebendable. ${ }^{24}$

However, several factors can affect the resistance of NiTi endodontic instruments, such as the manufacturing process, metallurgical design, instrument size, taper, helix angle, cross-sectional design, core diameter, file kinematics, heat treatment applied to the file, ${ }^{25,26,27}$ or even the temperature to which the instrument is subjected. ${ }^{20,28,29}$

Many cyclic fatigue test devices may be used with static or dynamic test models. In this study, the model used for the cyclic fatigue test was static, in which an instrument-fixed working length is bended and then rotated until fracture occurs with no axial movement,

Table. Mean and standard deviations of the number of cycles to failure (NCF), time to fracture (seconds) and the length of the fractured fragment $(\mathrm{mm})$ of the tested files

\begin{tabular}{lccc}
\hline Group & NFC & TF $(\mathrm{s})$ & Fractured Length (mm) \\
\hline Genius 25.04 & $1217.12 \pm 230.36^{a}$ & $208.65 \pm 39.49^{a}$ & $3.14 \pm 0.18^{a}$ \\
Genius 30.04 & $1365.58 \pm 224.81^{a}$ & $234.10 \pm 38.56^{a}$ & $3.86 \pm 0.54^{b}$ \\
Wave One Gold Primary & $881.7 \pm 108.04^{\mathrm{b}}$ & $151.15 \pm 18.52^{\mathrm{b}}$ & $2.37 \pm 0.50^{\mathrm{c}}$ \\
EdgeFile X1 & $6175.74 \pm 1608.99^{c}$ & $1058.7 \pm 275.82^{c}$ & $3.02 \pm 0.45^{a}$ \\
\hline
\end{tabular}

Different superscript letters indicate statistical significance $(p<.05)$. 

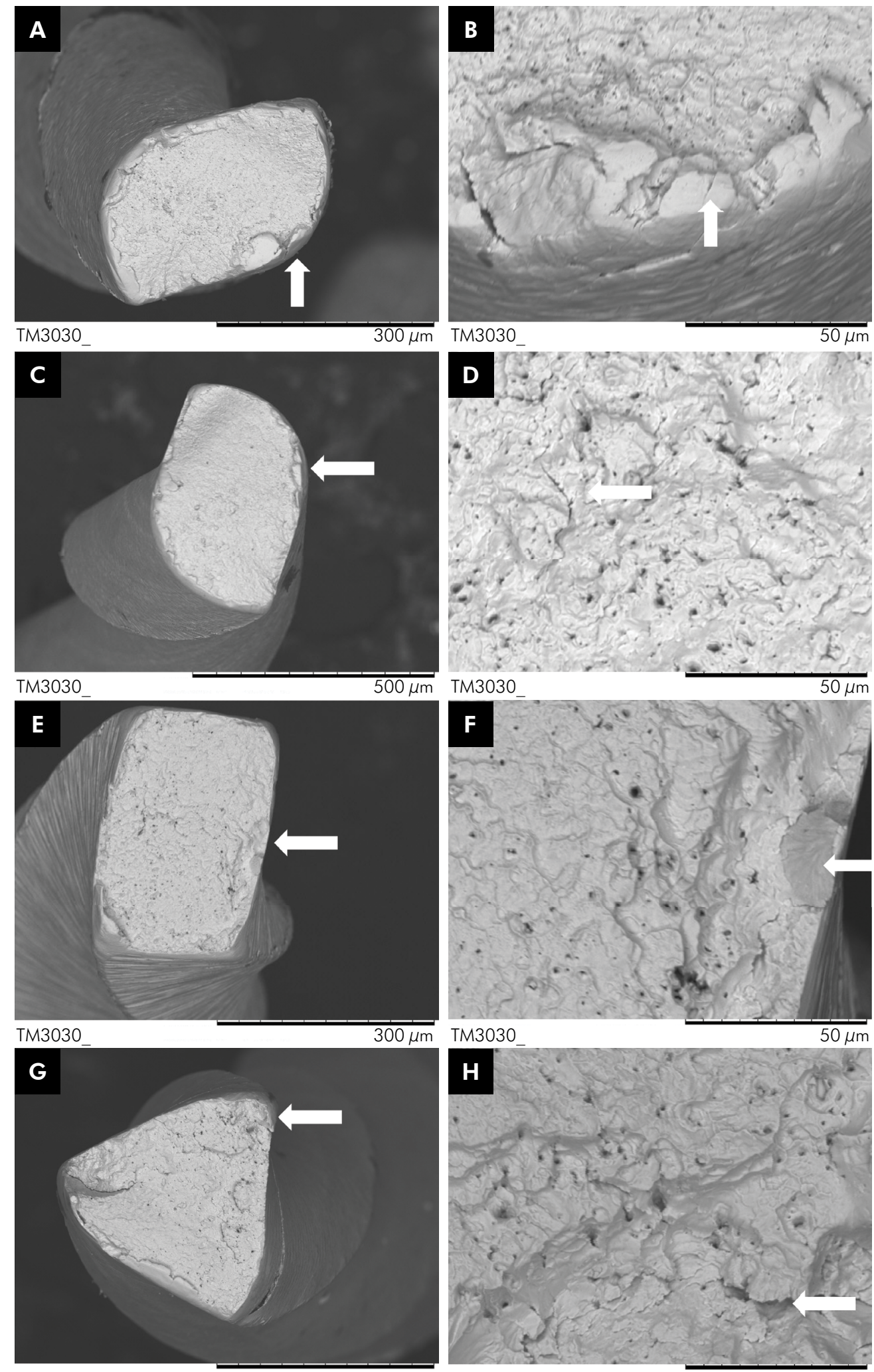

TM3030

TM3030

$50 \mu \mathrm{m}$

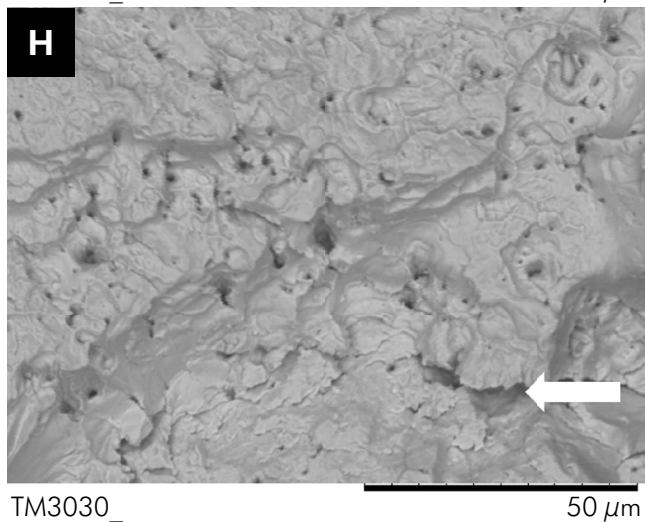

Figure 2. SEM Images after the fatigue cyclic test of Genius, WaveOne Gold Primary, and EdgeFile X1 instruments. General view of (A) Genius 25.04, (C) Genius 30.04, (E) WaveOne Gold Primary, and (G) EdgeFile X1 and high-magnification view of (B) Genius 25.04, (D) Genius 30.04, (F) WaveOne Gold Primary, and (H) EdgeFile X1 instruments, showing numerous dimples and fatigue striations, typical features of cyclic fatigue (white arrows). 
allowing for a precise trajectory in the simulated artificial canal in a stainless steel block, as used in previous studies. ${ }^{10,17,22,30,31}$ The advantages of the static model consist mainly in reducing variables, such as the amplitude of axial movements. ${ }^{10,20,31}$

With respect to the temperature of the in vitro test, the room temperature $\left(20^{\circ} \pm 1^{\circ} \mathrm{C}\right)$ was previously used to perform the cyclic fatigue test. ${ }^{19,21,32,33}$ However, recent findings have shown that NiTi martensite instruments operating at body temperature $\left(37^{\circ} \mathrm{C}\right)$ show a significant decrease in flexural resistance and consequently in NCF, since heating may induce a transition to a stiffer austenite phase, which is more susceptible to fatigue failure. ${ }^{20,28,29,34}$

The present study compared the cyclic fatigue resistance of the reciprocating Genius File and EdgeFile with WaveOne Gold. According to our results, the cyclic fatigue resistance of both Genius and EdgeFile systems was higher than that of WaveOne Gold, evidencing the highest fatigue resistance for EdgeFile. Thus, the null hypothesis of the present study was rejected.

This is the first study on the cyclic fatigue of a reciprocating EdgeFile instrument. A recent study has shown that reciprocating EdgeFile X1 induces low transportation, has a high centering ability, ${ }^{35}$ and shows similar shaping ability to iRaCe and XP-endo Shaper. ${ }^{36}$ According to the manufacturer, the annealed heat-treated Firewire NiTi increases flexibility, along with its $6 \%$ taper and a hyperbolic cross section. ${ }^{16}$ The association of a thermally treated alloy with a low core mass (taper .06) may explain the results obtained in this study. The elevated values for cyclic fatigue is in accordance with a previous study on a rotary EdgeFile X7, which presented the highest $\mathrm{NCF}$ values at different temperatures..$^{27}$ Additionally, another research study on rotary EdgeFiles X7 demonstrated that $\mathrm{CM}$ heat treatment has higher fatigue resistance than instruments without thermal or Fire-wire treatment. ${ }^{37}$

Supporting the findings of the present study, previous research studies have reported that the resistance to cyclic fatigue of S-shaped endodontic files with two cutting edges (e.g., Reciproc files) was greater than that of WaveOne files, ${ }^{38,39,40}$ attributing their findings to the different cross sections of the files. Cheung et al. ${ }^{41}$ also reported, through finite elemental analysis, that NiTi instruments with an S-shaped or triangular cross-section present better fatigue resistance than does a square or rectangular cross section.

Grande et al. ${ }^{42}$ compared the cyclic fatigue resistance of two different file cross sections: S-shaped Mtwo NiTi files (VDW) and the convex triangular ProTaper Universal files (Dentsply Maillefer). They found that Mtwo files, which have a smaller core mass, were more resistant to cyclic fatigue, in accordance with later findings, showing that files with a greater metal core mass have lower fracture resistance. ${ }^{29}$ There is no consensus about cross-sectional shape on cyclic fatigue resistance, but previous studies have indicated the dimension of the cross-sectional area as the most important factor in cyclic fatigue resistance than the type of alloy. ${ }^{8,40,41}$

The curvature of the artificial canal was located 5 -mm from the coronal end. Considering the taper of each file, the diameter at $5 \mathrm{~mm}$ from the tip (D5), which would be at the center of the curvature, shows different values. Wave One Gold has diameter 59 at D5, whereas Genius 25 is a 45 , Genius 30 is a 50 and EdgeFile is also a 50. Therefore, the greater taper and, consequently, the large core mass of Wave One Gold at D5, associated with the parallelogram cross section, may have influenced the low values on the cyclic fatigue test. Corroborating previous results and the findings of the present study, we suggest that, although the Genius File does not undergo heat treatment in the martensite phase, its higher cyclic fatigue resistance compared with WaveOne Gold might be because of the reduced taper and therefore a low core mass, explaining its superior performance, since cyclic fatigue decreases when file diameters are increased. ${ }^{45}$ In recent years, manufacturers have tended to produce lower taper files to ensure a more conservatively shaped canal. Lower taper files could enhance the fatigue resistance of NiTi endodontic files. ${ }^{45}$

Another major aspect is the difference in the reciprocating angle recommended by each manufacturer, which might explain the high resistance, since decreasing the reciprocation range of instruments results in an increased cyclic fatigue 
resistance ${ }^{46}$ A previous study regarding different reciprocation angles found that $90^{\circ} \mathrm{CW}-30^{\circ} \mathrm{CCW}$ was safer for enhancing instrument resistance to fatigue failure, when compared to instruments operating at greater angles. ${ }^{47}$ Additionally, the present study also corroborates the findings of Ozyurek et al. ${ }^{48}$ which showed the highest cyclic and bending resistance in double (S-shaped) curved canal for Genius files, when compared to WOG Primary and Reciproc Blue.

The fractured length of each file was at the center of the curvature or just above this point, confirming the positioning of the instruments. The SEM images showed regular fractographic appearance of cyclic fatigue with crack initiation areas and overload zones, which was similar in the four experimental groups.

\section{Conclusions}

Within the limitations of the present study, our results showed that EdgeFile X1 had significantly higher cyclic fatigue resistance. In addition, both Genius files showed higher cyclic fatigue resistance than WaveOne Gold Primary. Further research is necessary to analyze fatigue at different temperatures and with different tapers.

\section{Acknowledgments}

The authors thank Ultradent Products, Inc. for providing the files used in this study. This research was supported by Coordenação de Aperfeiçoamento de Pessoal de Nível Superior (CAPES) - Brazil.

\section{References}

1. Walia HM, Brantley WA, Gerstein H. An initial investigation of the bending and torsional properties of Nitinol root canal files. J Endod. 1988 Jul;14(7):346-51. https://doi.org/10.1016/S0099-2399(88)80196-1

2. Peters OA. Current challenges and concepts in the preparation of root canal systems: a review. J Endod. 2004 Aug;30(8):559-67. https://doi.org/10.1097/01.DON.0000129039.59003.9D

3. Gergi R, Rieily JA, Sader J, Naaman A. Comparison of canal transportation and centering ability of twisted files, PathfileProTaper system, and stainless steel hand K-files by using computed tomography. J Endod. 2010 May;36(5):904-7. https://doi.org/10.1016/i.joen.2009.12.038

4. El Batouty KM, Elmallah WE. Comparison of canal transportation and changes in canal curvature of two nickel-titanium rotary instruments. J Endod. 2011 Sep;37(9):1290-2. https://doi.org/10.1016/i.joen.2011.05.024

5. Spanaki-Voreadi AP, Kerezoudis NP, Zinelis S. Failure mechanism of ProTaper Ni-Ti rotary instruments during clinical use: fractographic analysis. Int Endod J. 2006 Mar;39(3):171-8. https://doi.org/10.1111/i.1365-2591.2006.01065.x

6. Wei X, Ling J, Jiang J, Huang X, Liu L. Modes of failure of ProTaper nickel-titanium rotary instruments after clinical use. J Endod. 2007 Mar;33(3):276-9. https://doi.org/10.1016/i.joen.2006.10.012

7. Tripi TR, Bonaccorso A, Tripi V, Condorelli GG, Rapisarda E. Defects in GT rotary instruments after use: an SEM study. J Endod. 2001 Dec;27(12):782-5. https://doi.org/10.1097/00004770-200112000-00018 PMID:11771591

8. Pruett JP, Clement DJ, Carnes DL Jr. Cyclic fatigue testing of nickel-titanium endodontic instruments. J Endod. 1997 Feb;23(2):77-85. https://doi.org/10.1016/S0099-2399(97)80250-6

9. Cheung GS, Darvell BW. Fatigue testing of a NiTi rotary instrument. Part 2: fractographic analysis. Int Endod J. 2007 Aug;40(8):619-25. https://doi.org/10.1111/j.1365-2591.2007.01256.x

10. Lopes HP, Elias CN, Vieira MV, Siqueira JF Jr, Mangelli M, Lopes WS, et al. Fatigue Life of Reciproc and Mtwo instruments subjected to static and dynamic tests. J Endod. 2013 May;39(5):693-6. https://doi.org/10.1016/i.joen.2012.11.048

11. Pedullà E, Franciosi G, Ounsi HF, Tricarico M, Rapisarda E, Grandini S. Cyclic fatigue resistance of nickel-titanium instruments after immersion in irrigant solutions with or without surfactants. J Endod. 2014 Aug;40(8):1245-9. https://doi.org/10.1016/j.joen.2014.02.005

12. Dagna A, Poggio C, Beltrami R, Colombo M, Chiesa M, Bianchi S. Cyclic fatigue resistance of OneShape, Reciproc, and WaveOne: an in vitro comparative study. J Conserv Dent. 2014 May;17(3):250-4. https://doi.org/10.4103/0972-0707.131788

13. Webber J. Shaping canals with confidence: WaveOne GOLD single-file reciprocating system. Int Dent African Ed. 2015;6(3):6-17.

14. Dentsply Sirona. WaveOne Gold. York, 2018 [cited 2018 Nov]. Available from: https://www.dentsplysirona.com/en-us/products/ endodontics/waveone-gold.html\#waveonegoldfiles

15. Ultradent Products. Endo-Eze ${ }^{T M}$ Genius ${ }^{\circledR}$ System. South Jordan, 2018 [cited 2018 Nov]. Avaliable from. https://www.ultradent.com/enus/Dental-Products-Supplies/Endodontics/Instrumentation/endo-eze-genius-motor-contra-angle-and-files-system/Pages/default.aspx 
- Cyclic fatigue resistance of novel Genius and Edgefile nickel-titanium reciprocating instruments

16. EdgeEndo ${ }^{T M}$. EdgeFile ${ }^{\circledR}$ X-1 Heat Treated Fire-Wire ${ }^{T M}$ NiTi Reciprocating Files. Albuquerque, 2018 [cited 2018 Nov]. Avaliable from: https://edgeendo.com/wp-content/uploads/2015/08/DFU-EdgeFile-x1.pdf

17. Özyürek T. Cyclic fatigue resistance of reciproc, waveone, and waveone gold nickel-titanium instruments. J Endod. 2016 Oct;42(10):1536-9. https://doi.org/10.1016/i.joen.2016.06.019

18. Özyürek T, Uslu G, İnan U. A Comparison of the cyclic fatigue resistance of used and new glide path files. J Endod. 2017 Mar;43(3):477-80. https://doi.org/10.1016/i.joen.2016.10.044

19. Alcalde MP, Duarte MA, Bramante CM, de Vasconselos BC, Tanomaru-Filho M, Guerreiro-Tanomaru JM, et al. Cyclic fatigue and torsional strength of three different thermally treated reciprocating nickel-titanium instruments. Clin Oral Investig. 2018 May;22(4):1865-71. https://doi.org/10.1007/s00784-017-2295-8

20. Klymus ME, Alcalde MP, Vivan RR, Só MV, Vasconselos BC, Duarte MA. Effect of temperature on the cyclic fatigue resistance of thermally treated reciprocating instruments. Clin Oral Investig. 2018 Nov;(Nov):1-6. https://doi.org/10.1007/s00784-018-2718-1

21. Gündoğar M, Özyürek T. Cyclic fatigue resistance of oneshape, HyFlex EDM, WaveOne Gold, and reciproc blue nickel-titanium instruments. J Endod. 2017 Jul;43(7):1192-6. https://doi.org/10.1016/i.joen.2017.03.009

22. Alcalde MP, Tanomaru-Filho M, Bramante CM, Duarte MA, Guerreiro-Tanomaru JM, Camilo-Pinto J, et al. Cyclic and torsional fatigue resistance of reciprocating single files manufactured by different nickel-titanium alloys. J Endod. 2017 Jul;43(7):1186-91. https://doi.org/10.1016/i.joen.2017.03.008

23. Gambarini G, Grande NM, Plotino G, Somma F, Garala M, De Luca M, et al. Fatigue resistance of engine-driven rotary nickel-titanium instruments produced by new manufacturing methods. J Endod. 2008 Aug;34(8):1003-5. https://doi.org/10.1016/j.joen.2008.05.007

24. Zupanc J, Vahdat-Pajouh N, Schäfer E. New thermomechanically treated NiTi alloys - a review. Int Endod J. 2018 Oct;51(10):1088-103. https://doi.org/10.1111/iej.12924

25. Lopes HP, Gambarra-Soares T, Elias CN, Siqueira JF Jr, Inojosa IF, Lopes WS, et al. Comparison of the mechanical properties of rotary instruments made of conventional nickel-titanium wire, M-wire, or nickel-titanium alloy in R-phase. J Endod. 2013 Apr;39(4):516-20. https://doi.org/10.1016/i.joen.2012.12.006

26. Pereira ES, Peixoto IF, Viana AC, Oliveira II, Gonzalez BM, Buono VT, et al. Physical and mechanical properties of a thermomechanically treated $\mathrm{NiTi}$ wire used in the manufacture of rotary endodontic instruments. Int Endod J. 2012 May;45(5):469-74. https://doi.org/10.1111/j.1365-2591.2011.01998.x

27. Turpin YL, Chagneau F, Vulcain JM. Impact of two theoretical cross-sections on torsional and bending stresses of nickel-titanium root canal instrument models. J Endod. 2000 Jul;26(7):414-7. https://doi.org/10.1097/00004770-200007000-00009

28. Dosanjh A, Paurazas S, Askar M. The effect of temperature on cyclic fatigue of nickel-titanium rotary endodontic instruments. J Endod. 2017 May;43(5):823-6. https://doi.org/10.1016/j.joen.2016.12.026

29. Jamleh A, Yahata Y, Ebihara A, Atmeh AR, Bakhsh T, Suda H. Performance of NiTi endodontic instrument under different temperatures. Odontology. 2016 Sep;104(3):324-8. https://doi.org/10.1007/s10266-015-0214-5

30. Almeida-Gomes F, de Matos HR, Nunes RF, Arrais AM, Ferreira-Maniglia C, de Morais Vitoriano M, et al. Cyclic fatigue resistance of different continuous rotation and reciprocating endodontic systems. Indian J Dent Res. 2016 May-Jun;27(3):278-82. https://doi.org/10.4103/0970-9290.186244

31. Wan J, Rasimick BJ, Musikant BL, Deutsch AS. A comparison of cyclic fatigue resistance in reciprocating and rotary nickel-titanium instruments. Aust Endod J. 2011 Dec;37(3):122-7. https://doi.org/10.1111/j.1747-4477.2010.00222.x

32. De-Deus G, Silva EJ, Vieira VT, Belladonna FG, Elias CN, Plotino G, et al. Blue thermomechanical treatment optimizes fatigue resistance and flexibility of the Reciproc files. J Endod. 2017 Mar;43(3):462-6. https://doi.org/10.1016/i.joen.2016.10.039

33. Topçuoğlu HS, Düzgün S, Akłı A, Topçuoğlu G. Laboratory comparison of cyclic fatigue resistance of WaveOne Gold, Reciproc and WaveOne files in canals with a double curvature. Int Endod J. 2017 Jul;50(7):713-7. https://doi.org/10.1111/iej.12674

34. Vasconcelos RA, Murphy S, Carvalho CA, Govindjee RG, Govindjee S, Peters OA. Evidence for reduced fatigue resistance of contemporary rotary instruments exposed to body temperature. J Endod. 2016 May;42(5):782-7. https://doi.org/10.1016/i.joen.2016.01.025

35. Hasheminia SM, Farhad A, Sheikhi M, Soltani P, Hendi SS, Ahmadi M. Cone-beam computed tomographic analysis of canal transportation and centering ability of single-file systems. J Endod. 2018 Dec;44(12):1788-91.

36. Versiani MA, Carvalho KK, Mazzi-Chaves JF, Sousa-Neto MD. Micro-computed tomographic evaluation of the shaping ability of XP-endo Shaper, iRaCe, and EdgeFile Systems in long oval-shaped canals. J Endod. 2018 Mar;44(3):489-95. https://doi.org/10.1016/i.joen.2017.09.008 PMID:29273492

37. Tanomaru-Filho M, Galletti Espir C, Carolina Venção A, Macedo-Serrano N, Camilo-Pinto J, Guerreiro-Tanomaru J. Cyclic fatigue resistance of heat-treated nickel-titanium instruments. Iran Endod J. 2018;13(3):312-7.

38. Plotino G, Grande NM, Testarelli L, Gambarini G. Cyclic fatigue of Reciproc and WaveOne reciprocating instruments. Int Endod J. 2012 Jul;45(7):614-8. https://doi.org/10.1111/i.1365-2591.2012.02015.x 
Bueno CRE, Cury MTS, Vasques AMV, Sivieri-Araújo G, Jacinto RC, Gomes-Filho JE et al.

39. Arias A, Perez-Higueras JJ, Macorra JC. Differences in cyclic fatigue resistance at apical and coronal levels of Reciproc and WaveOne new files. J Endod. 2012 Sep;38(9):1244-8. https://doi.org/10.1016/i.joen.2012.05.022

40. Kim HC, Kwak SW, Cheung GS, Ko DH, Chung SM, Lee W. Cyclic fatigue and torsional resistance of two new nickel-titanium instruments used in reciprocation motion: reciproc versus WaveOne. J Endod. 2012 Apr;38(4):541-4. https://doi.org/10.1016/i.joen.2011.11.014

41. Cheung GS, Zhang EW, Zheng YF. A numerical method for predicting the bending fatigue life of NiTi and stainless steel root canal instruments. Int Endod J. 2011 Apr;44(4):357-61. https://doi.org/10.1111/i.1365-2591.2010.01838.x

42. Grande NM, Plotino G, Pecci R, Bedini R, Malagnino VA, Somma F. Cyclic fatigue resistance and threedimensional analysis of instruments from two nickel-titanium rotary systems. Int Endod J. 2006 Oct;39(10):755-63. https://doi.org/10.1111/j.1365-2591.2006.01143.x

43. Pedullà E, Grande NM, Plotino G, Gambarini G, Rapisarda E. Influence of continuous or reciprocating motion on cyclic fatigue resistance of 4 different nickel-titanium rotary instruments. J Endod. 2013 Feb;39(2):258-61. https://doi.org/10.1016/i.joen.2012.10.025

44. Capar ID, Kaval ME, Ertas $\mathrm{H}$, Sen BH. Comparison of the cyclic fatigue resistance of 5 different rotary pathfinding instruments made of conventional nickel-titanium wire, M-wire, and controlled memory wire. J Endod. 2015 Apr;41(4):535-8. https://doi.org/10.1016/i.joen.2014.11.008

45. Adıgüzel M, Capar ID. Comparison of cyclic fatigue resistance of WaveOne and WaveOne Gold small, primary, and large instruments. J Endod. 2017 Apr;43(4):623-7. https://doi.org/10.1016/i.joen.2016.11.021

46. Saber SD, Abu El Sadat SM. Effect of altering the reciprocation range on the fatigue life and the shaping ability of WaveOne nickeltitanium instruments. J Endod. 2013 May;39(5):685-8. https://doi.org/10.1016/i.joen.2012.12.007

47. Gambarini G, Rubini AG, Al Sudani D, Gergi R, Culla A, De Angelis F, et al. Influence of different angles of reciprocation on the cyclic fatigue of nickel-titanium endodontic instruments. J Endod. 2012 Oct;38(10):1408-11. https://doi.org/10.1016/i.joen.2012.05.019

48. Özyürek T, Gündoğar M, Yılmaz K, Uslu G. Bending resistance and cyclic fatigue life of Reciproc Blve, WaveOne Gold, and Genius files in a double (S-shaped) curved canal. J Dent Res Dent Clin Dent Prospects. 2017;11(4):241-6. 